
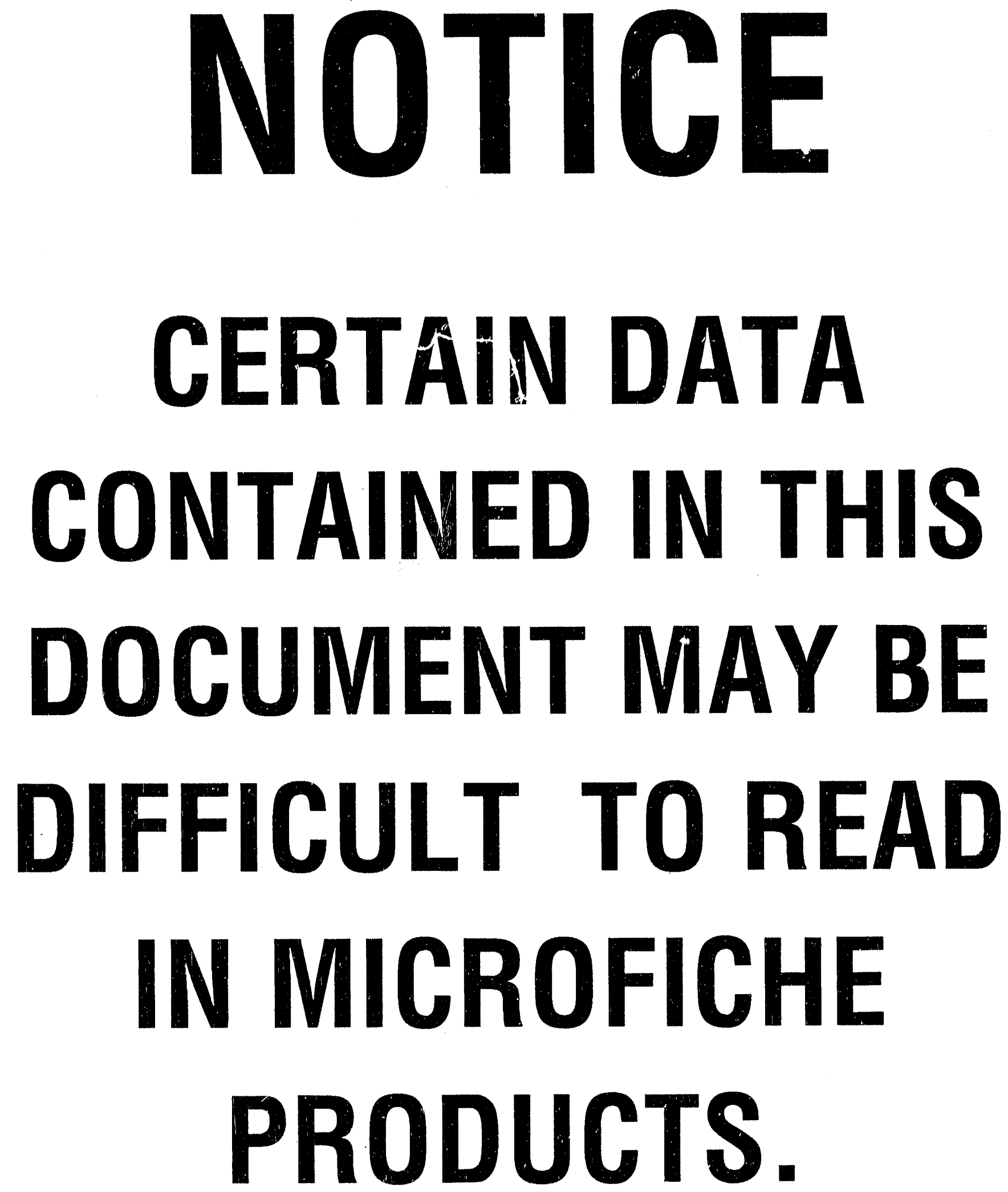
DOE/ER/45133--4

DE92 015050

\title{
STUDY OF MULTICOMPONENT DIFFUSION AND TRANSPORT PHENOMENA
}

\author{
ANNUAL PROGRESS REPORT \\ FOR PERIOD $7 / 1 / 91-6 / 30 / 92$ \\ Hiroshi Sato \\ School of Materials Engineering \\ Purdue University \\ West Lafayette, IN 47907
}

Grant No. DE-FG02-84ER45133

\section{DISCLAIMER}

This report was prepared as an account of work sponsored by an agency of the United States Government. Neither the United States Government nor any agency thereof, nor any of their employees, makes any warranty, express or implied, or assumes any legal liability or responsiemplnyes, me accuracy, completeness, or usefulness of any information, apparatus, product, or bility for the accuracy, completenes, or use would not infringe priv tely owned rights. Refer-

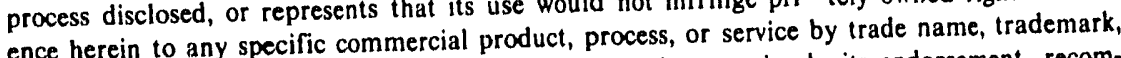
ence herein to any specific commercial product, process, or service by its endorsement, recommanufacturer, or otherwise does not necessarily constitute or imply its endorsement, The views mendation, or favoring by the United States Government or any agency reflect those of the and opinions of authors expressed herein do not

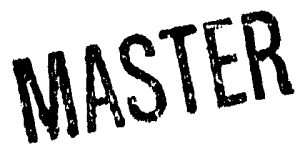




\section{Summary of Scientific Progress}

A stendy progress is zeir z made in all areas of research proposed for this pericd. Indeed. an zacitang progress is acw sogeced in the frequency dependence of ionic conductivily and in atomiste araments of kem:an jifusion based on the progress made in this period. In the following, a briet acoun si work done during this period (February, 1991 - January, 1992) is given.

1. Application of the Clusier Variation Method for the Calculation of the Percolation Problem

The problem whether P-.ntumina type compounds can become mixed corductors by doping mixed valent ions ivis ireated by the Cluster Variation Method. The same problem was treated by a higher degree of approximation this time and was presented at the SSI (Solid State Ionics) - 8 meeting held in October, 1991 at Lake Louise, Alberta, Canada (paper \#6). Based on the assumption that the electronic conduction in $\beta$-alumina is due to the hopping of small polarons to the nearest neighboring ions on the octahedral sites in the spinel block similar to that in magnetite, the triangle-tetrahedron approximation of the Cluster Variation Method gives the percolation threshold of 0.39 for the required concentration of mixed valent ions on the octahedral sites compared to the value 0.24 obtained by the pair approximation. A specific interest of this work is, in additon to the intrinsic interest in making $\beta$-alumina type compounds a mixed conductor, to treat a percolation problem in the specific two dimensional conduction layers consisting of two Kagore layers connected by a middle triangular lattice layer in the $\beta$ alumina type structure. 


\section{Atomistic Treatments of Chemical Diffusion}

The basis for chemical diffusion process has been first established by Darken by means of irreversible thermodynamics. However, Darken's formalism corresponds to the molecular field approximation of the problem. This is due to the fact that the formalism of irreversible thermodynamics deals with the motion of a homogeneous assembly rather than the average of the time correlation of the motion of individual particles. In order to deal with such a problem, it is necessary to treat the problem by statistical mechanics from an atomistic point of view.

Even in the atomistic approach, we found that the original PPM gives a similar result to that of Darken even in the pair approximation. This difficulty is found to be removed by the application of the time conversion process based on the pair approximation of the PPM.

The point approximation (molecular field approximation) of the PPM is, on the other hand, self consistent and does not require the time conversion process. Although this is equivalent to the Darken's approach, we treated the chemical diffusion process in ternary systems with the point approximation from an atomistic point of view in order to examine the feasibility of the treatment by the atomistic approach in the higher approximation. The papers $\# 1$ and \#2 represent these results.

\section{Frequency Dependence of Ionic Conductivity}

As stated in the research program for this funding period, the major aim of this project is to understand the mechanism of the relaxation process generally observed in structurally disordered solid electrolytes. The process is often termed "universal dielectric response" if the frequency dependence of conductivity and permittivity is considered. The relaxation process shows distinct non-Debye characteristics. At this moment, no appropriate analytical theory exists to explain this behavior. 
We found that the pair approximation of the PPM with the time conversion process essentially deal with this problem appropriately (paper \#5 which was presented at SS1-8 meeting, last October). Although numerical calculations for individual cases are yet to be made, this work represents the most exciting progress made this year.

\section{Diffusion Process in Semiconductors}

Although the formularion of diffusion equations characteristic so semiconductors is completed, the cluster size required for a systematic treatment by the PPAI of a variery of problems in semiconductors becomes extremely large and we found this makes the analytical treatment not feasible. Because of exciting progress in the treatment of frequenc: dependence of ionic conductivity and in atomistic chemical diffusion, the effort on this project is reduced at this moment.

\section{Formalism of the Path Probability Method}

Upon the invitation from the Japan Institute of Metals, a review paper "Path Probability Method of Irreversible Statistical Mechanics" was written for Materials Transactions, JIM (paper \#4). Here, the formalism of the Path Probability method is examined in order to explore the applicability of the method to a variety of kinetic problems, especially to transport problems. This work was instrumental to the progress of the research on the frequency dependence of ionic conductivity.

\section{Theoretical Aspects of Mixed Alkali Effect}

Upon the invitation of the American Ceramic Society, a review paper "Theoretica! Aspects of Mixed Alkali Effect" was written in Ceramic Transactions, Vol. 20, Glasses for Electronic Applications (paper \#3). Here, it is shown that, by means of the pair approximation of the PPM with time conversion, how general characteristics of mixed alkali effects can be 
explained as general characters of ionic conductivity in interacting binary systems. Here, the concept of percolation efficiency defined by the ratio of the ionic conductivity at zero frequency and at infinite frequency $\sigma(0) / \sigma(\infty)$ plays an important role. Therefore, the study of the frequency dependence of ionic sonductivity constirutes an important part of the study of mixed alkilli effect. 


\section{List of Publications}

1. H. Zhang, A. Datta and H. Sato, "Atomistic Treatment of Chemical Diffusion in Multicomponent Alloys: Relation between Intrinsic Dif̂usion Coefficient and Diffusion Coefficients in the Laboratory Frame," in Atomic Migration and Defects in Materials, edited by D. Cupta, H. Jain and R. W. Siegel, Sci-Tech Pubitarticn (?991) pp. 107-114.

2. H. Sato and A. Datta, "Atonistic Treatment or Chemical Dirision Phenomena," in

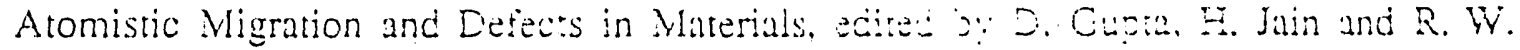
Siegel, Sci-Tech Pubitcation (1991), pp. $115-120$.

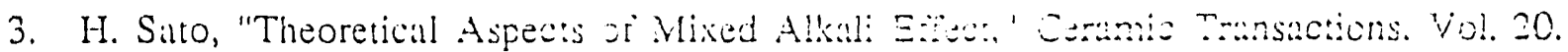

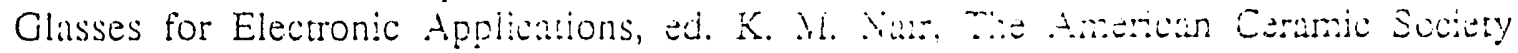
(1991), pp. 19-39.

4. H. Sato, "Path Probability Method of Irreversibie Statistical Mechanics: An Overvie:w."

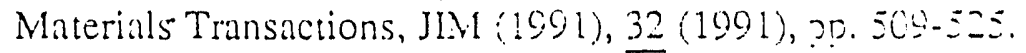

5. H. Sato, T. Ishikawa and K. Funke, "Frequenc: Depencence or Icnic Conductivity in Interacting Lattice Gas Systems," Solid State Ionics (aceptedi).

6. A. Datta, R. Kikuchi and H. Sato, Percolation Threshoid Eor Electronic Conduction in $\beta$ Alumina Type Compounds, II, Solid State Ionics (accepted). 

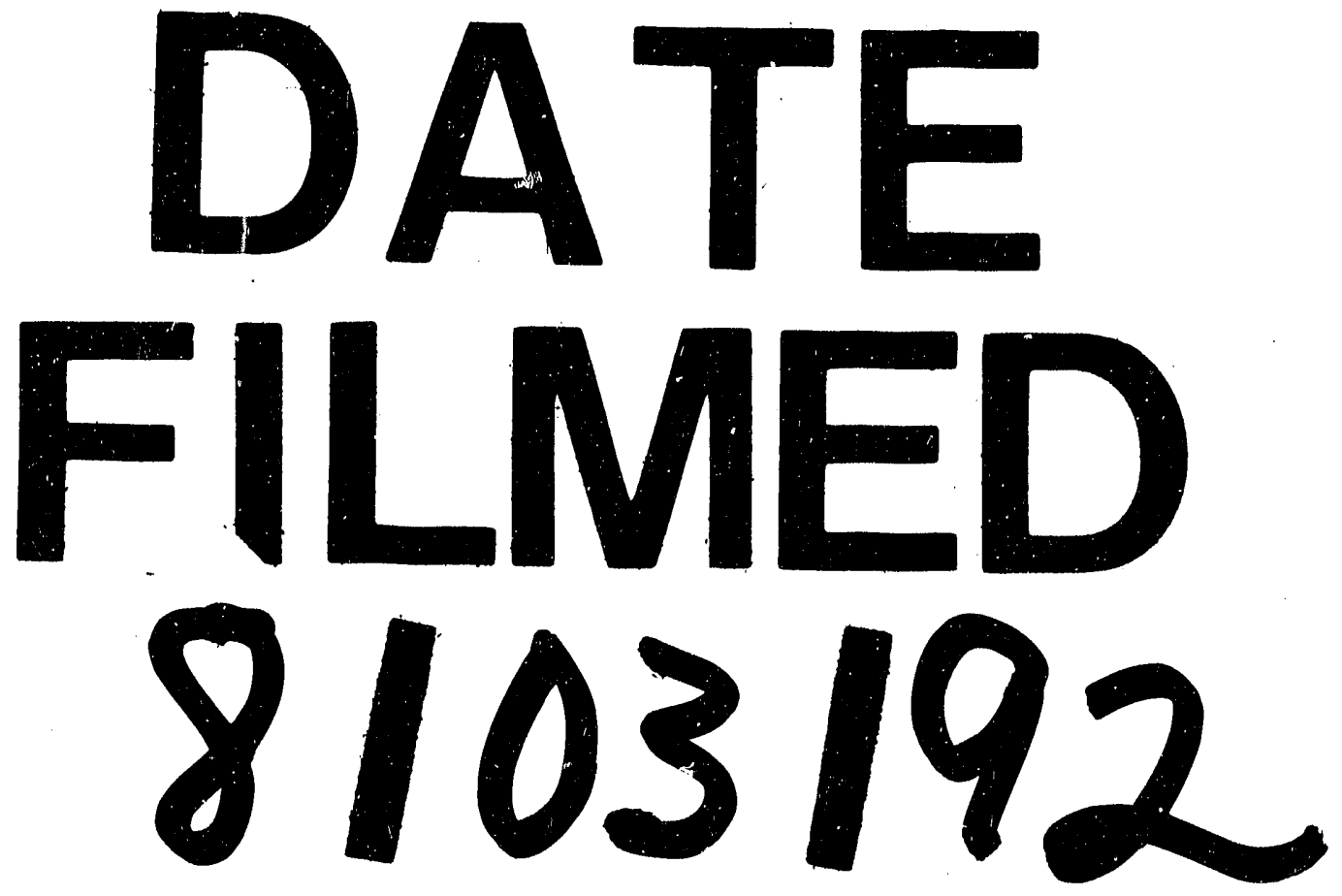

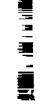


